\title{
Systemic Treatment of Advanced Gastroenteropancreatic Neuroendocrine Tumors in Korea: Literature Review and Expert Opinion
}

\section{Changhoon Yoo ${ }^{1}$, Chung Ryul Oh', Seung-Tae Kim², Woo Kyun Bae ${ }^{3}$, Hye-Jin Choi ${ }^{4}$, Do-Youn Oh$^{5}$, Myung-Ah Lee ${ }^{6}$, Baek-Yeol Ryoo}

${ }^{1}$ Department of Oncology, Asan Medical Center, University of Ulsan College of Medicine, Seoul, ${ }^{2}$ Division of Hematology-Oncology, Department of Medicine, Samsung Medical Center, Sungkyunkwan University School of Medicine, Seoul, ${ }^{3}$ Division of Hematology-Oncology, Department of Internal Medicine, Chonnam National University Medical School, Gwangju, ${ }^{4}$ Division of Medical Oncology, Department of Internal Medicine, Yonsei Cancer Center, Yonsei University College of Medicine, Seoul, ${ }^{5}$ Division of Medical Oncology, Department of Internal Medicine, Seoul National University Hospital, Cancer Research Institute, Seoul National University College of Medicine, Seoul, ${ }^{6}$ Division of Medical Oncology, Department of Internal Medicine, Seoul St. Mary's Hospital, Catholic Cancer Research Institute, College of Medicine, The Catholic University of Korea, Seoul, Korea

Neuroendocrine tumors (NETs) are a group of malignancies arising from neuroendocrine cells and frequently originate in the gastrointestinal tract and pancreas. Although curative resection is the main treatment for localized disease, systemic therapy is needed for relapsed or metastatic/unresectable gastroenteropancreatic NETs (GEP-NETs). Although there are several NET treatment guidelines from various countries, the geographical discrepancies between patient clinical characteristics, the regulatory approval status for therapeutic agents, and medical practices necessitate specific guidelines for Korean patients. We here provide a consensus review of the diagnosis, staging and systemic treatment of Korean GEP-NET patients. Systemic therapy options and the current Korean expert consensus on these treatments, including somatostatin analogs, targeted therapies such as everolimus and sunitinib, peptide receptor radionuclide treatments, and cytotoxic chemotherapies are addressed.

Key words Neuroendocrine tumor, Lanreotide, Octreotide, Everolimus, Sunitinib, Peptide receptor radionuclide therapy, Capecitabine, Temozolomide

\section{Introduction}

Neuroendocrine tumors (NETs) are a rare, heterogeneous group of malignancies originating from the neuroendocrine cells of various organs. NETs are classified based on their embryonic origin as foregut (bronchial, gastric, duodenal, pancreatic), midgut (ileal, jejunal, cecal, proximal colonic), or hindgut (distal colonic, rectal). More than $50 \%$ of NETs arise in the gastrointestinal tract and pancreas [1,2]. Although they are a relatively uncommon tumor, constituting approximately $2 \%$ of all neoplasms, the incidence and prevalence of NETs has increased substantially over the past three decades [1,3]. Data from population-based registries in the United States indicate that $51 \%$ of NETs originate from the gastrointestinal tract, 27\% from the lungs, and 6\% from the pancreas [2]. There are reported regional and ethnic differences in the distribution of primary NET sites [1-5]. While lung and jejunal/ileal NETs are more common in Caucasian patients compared to other ethnic populations [3], the incidence of hindgut (especially rectal) NETs is higher in Asian patients, including those from Korea and Japan [2,5-7]. A previous multicenter analy- sis by the Gastrointestinal Pathology Study Group of Korean Society of Pathologists, comprising 4,951 pathology reports from 29 Korean hospitals, has indicated that the most common primary site of a gastroenteropancreatic (GEP)-NET in Korean patients is the rectum (48.0\%), followed by the stomach $(14.6 \%)$, pancreas $(8.7 \%)$, colon $(7.9 \%)$, and small intestine $(7.7 \%)$ [5]. A previous Korean single-center retrospective study, which included a total of 371 NETs (including those of lung origin) treated between 1996 and 2007, reported that the hindgut $(38.3 \%)$ was the most common site of origin, followed by the pancreas $(16.2 \%)$, foregut $(13.5 \%)$ and midgut $(4.9 \%)$ [6].

Clinically, NETs are regarded as functional if they are associated with symptoms of hormonal hypersecretion, but nonfunctional if they have no hormone-related clinical features [3]. The manifestation of any GEP-NETs can include non-specific symptoms such as pain, nausea and vomiting, and, in some cases, anemia due to intestinal blood loss. Pain may be due to local tumor invasion, bowel obstruction, or mesenteric ischemia. The most advanced GEP-NETs are non-functioning and usually present with a mass effect of the primary tumor
Correspondence: Myung-Ah Lee

Division of Medical Oncology, Department of Internal Medicine, Seoul St. Mary's Hospital, Catholic Cancer Research Institute, College of Medicine,

The Catholic University of Korea, 222 Banpo-daero, Seocho-gu, Seoul 06591, Korea Tel: 82-2-2258-6044 Fax: 82-2-599-3589 E-mail: angelamd@catholic.ac.kr

\section{Co-correspondence: Baek-Yeol Ryoo \\ Department of Oncology, Asan Medical Center, University of Ulsan College of Medicine, 88 Olympic-ro 43-gil, Songpa-gu, Seoul 05505, Korea Tel: 82-2-3010-3211 Fax: 82-2-3010-6961 E-mail: ryooby@amc.seoul.kr}

Received November 23, 2020 Accepted December 28, 2020 Published Online December 29, 2020 
Table 1. Summary of prior large-randomized trials of different GEP-NET treatments

\begin{tabular}{|c|c|c|c|c|c|}
\hline Trial/Agents & Tumor type & $\begin{array}{c}\text { No. of } \\
\text { patients }\end{array}$ & $\begin{array}{l}\text { Response } \\
\text { rate }(\%)\end{array}$ & $\begin{array}{l}\text { Progression-free } \\
\text { survival (mo) }\end{array}$ & $\begin{array}{l}\text { Hazard ratio } \\
\text { (95\% CI) }\end{array}$ \\
\hline PROMID $^{\text {a) }}$ [9] & Midgut NET & & & & \\
\hline Octreotide & & 42 & - & 14.3 & $0.34(0.20-0.59)$ \\
\hline Placebo & & 43 & - & 6.0 & \\
\hline CLARINET [10] & GEP-NETs & & & & \\
\hline Lanreotide & & 101 & - & Not reached & $0.47(0.30-0.73)$ \\
\hline Placebo & & 103 & - & 18.0 & \\
\hline RADIANT-3 [11] & Pancreatic NET & & & & \\
\hline Everolimus & & 204 & 5 & 11.0 & $0.35(0.27-0.45)$ \\
\hline Placebo & & 203 & 2 & 4.6 & \\
\hline RADIANT-4 [12] & Lung and GI NETs & & & & \\
\hline Everolimus & & 205 & 2 & 11.0 & $0.48(0.35-0.67)$ \\
\hline Placebo & & 97 & 1 & 3.9 & \\
\hline Raymond et al. [13] & Pancreatic NET & & & & \\
\hline Sunitinib & & 86 & 9.3 & 11.4 & $0.42(0.26-0.66)$ \\
\hline Placebo & & 85 & 0 & 5.5 & \\
\hline NETTER-1 [14] & Midgut NET & & & & \\
\hline${ }^{177} \mathrm{Lu}$-DOTATATE & & 116 & 18 & Not reached & $0.21(0.13-0.33)$ \\
\hline High-dose octreotide & & 113 & 3 & 8.4 & \\
\hline Kunz et al. [15] & Pancreatic NET & & & & \\
\hline CAPTEM & & 72 & 33.3 & 22.7 & $0.58(0.36-0.93)$ \\
\hline Temozolomide & & 72 & 27.8 & 14.4 & \\
\hline
\end{tabular}

CAPTEM, capecitabine plus temozolomide; CI, confidence interval; GEP, gastroenteropancreatic; GI, gastrointestinal; NET, neuroendocrine

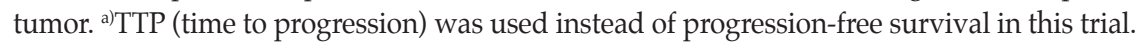

Table 2. Evidence-based landscape of the treatment strategies for gastroenteropancreatic neuroendocrine tumors

\begin{tabular}{|c|c|c|c|c|c|}
\hline & Octreotide LAR [9] & Lanreotide [10] & ${ }^{177} \mathrm{Lu}$-DOTATATE [14] & Sunitinib [13] & Everolimus [12] \\
\hline Differentiation & & & Well-differentiated & & \\
\hline SSTR positive & $\mathrm{O}$ & $\mathrm{O}$ & $\mathrm{O}$ & & \\
\hline Disease status & Treatment-naive & Stable & Progressive & Progressive & Progressive \\
\hline \multicolumn{6}{|l|}{ Origin site } \\
\hline Stomach & & & & & $\mathrm{O}$ \\
\hline Pancreas & & $\mathrm{O}$ & & $\mathrm{O}$ & $\mathrm{O}$ \\
\hline Small intestine appendix & $\mathrm{O}$ & $\mathrm{O}$ & $\mathrm{O}$ & & $\mathrm{O}$ \\
\hline Large intestine rectum & & $\mathrm{O}$ & & & $\mathrm{O}$ \\
\hline
\end{tabular}

DOTATATE, DOTA-octreotate; oxodotreotide, DOTA-(Tyr3)-octreotate, and DOTA-0-Tyr3-Octreotate; SSTR, somatostatin receptor.

or metastases (usually in the liver) [2,6].

Surgery or endoscopic resection are curative treatments for resectable NETs, but a significant proportion of patients show a recurrence after curative-intent resection, and up to $20 \%$ $28 \%$ of patients present with metastatic disease at the time of diagnosis [2,6-8]. In a previous retrospective report from a Korean tertiary referral institution, $8.1 \%$ and $18.1 \%$ of patients had locally advanced and metastatic disease at the time of diagnosis, which is comparable to the epidemiology data from other countries [6]. Systemic therapy is the mainstay of clinical management in these cases. Although various types of systemic therapy, including somatostatin analogs (SSAs), targeted therapy, peptide receptor radionuclide therapy (PRRT), and cytotoxic chemotherapy, have been evaluated and approved for the management of advanced GEP-NETs (Tables 1 and 2), few randomized trials to date have compared the outcomes of each treatment option. This has made decision-making for individual patients more difficult. An 
expansion of the treatment landscape for advanced GEPNETs brings with it the challenges of selecting the optimal first-line agent and of deciding an appropriate sequence of regimens. A paucity of biological, molecular, and genomic information, and an absence of data from rigorous trials, limits the validity of many publications detailing the management of this disease. Because most of the current GEP-NET management strategies are based on a synthesis of experiences, local practice patterns, or archaic concepts, there are many aspects of GEP-NET therapies that remain unclear and controversial.

There are currently several published guidelines for GEPNET management such as those of the European Neuroendocrine Tumor Society (ENETS), North American Neuroendocrine Tumor Society (NANETS), European Society of Medical Oncology (ESMO), and National Comprehensive Cancer Network (NCCN). Nevertheless, the geographical discrepancies between GEP-NET patient clinical characteristics, the regulatory approval status for therapeutic agents, and medical practices to treat these cancers, necessitate specific guidelines for Korean patients [2-5]. This present review discusses current consensus statements along with key aspects of the management of Korean GEP-NET patients.

\section{Diagnostic Work-ups}

\section{Pathological diagnosis}

The current pathologic assessments used to determine the appropriate therapeutic approaches for GEP-NET patients follow the recently revised World Health Organization classification for neuroendocrine neoplasms (Table 3) [16,17]. Although both mitotic counts and Ki-67 expression are key indicators for the determination of NET grade, Ki-67 has been regarded as a more reliable indicator for systemic therapy. GEP-NETs of grade 1-2 have been traditionally referred to as well-differentiated NETs and the revised World Health Organization (WHO) classification now includes NET grade 3 in this category.

\section{Biochemical markers}

Depending on the primary tumor sites or patient symptoms, measurement of the serum levels of gastrin glucagon, insulin, vasoactive intestinal peptide, chromogranin- $\mathrm{A}$, and urine 5-hydroxyindoleacetic acid should be considered However, these biomarkers are not conclusive indicators for the diagnosis of a GEP-NET [18].

\section{Functional imaging}

In addition to computed tomography (CT) and magnetic resonance imaging, functional imaging studies using radi-
Table 3. Revised WHO classification of GEP-NETs $[16,17]$

Ki-67 index (\%) Mitotic index

\begin{tabular}{llr} 
Well-differentiated NENs & & \\
NET grade 1 & $<3$ & $<2 / 10 \mathrm{HPF}$ \\
NET grade 2 & $3-20$ & $2-20 / 10 \mathrm{HPF}$ \\
NET grade 3 & $>20$ & $>20 / 10 \mathrm{HPF}$ \\
Poorly differentiated NENs & & \\
$\quad$ NEC grade 3 & $>20$ & $>20 / 10 \mathrm{HPF}$ \\
\hline
\end{tabular}

GEP, gastroenteropancreatic; HPF, high-power field; NEC, neuroendocrine carcinoma; NEN, neuroendocrine neoplasm; NET, neuroendocrine tumor; WHO, World Health Organization.

olabeled SSAs have a role in detecting the primary tumor site for GEP-NETs that was not revealed using conventional endoscopic or imaging studies. Radiolabeled SSAs also provide information on the biologic features of GEP-NETs by measuring somatostatin receptor (SSTR) expression. Although ${ }^{111}$ In-octreotide has been used for diagnostic or staging evaluations, with a reported sensitivity of $61 \%$ $96 \%$, this modality has several key limitations as follows: (1) reduced sensitivity in smaller lesions and in lesions exhibiting low receptor density; (2) requirement for a 2-day imaging protocol; and (3) potential interference by co-administration of therapeutic SSAs [19].

Novel SSTR-targeting functional imaging techniques use ${ }^{68} \mathrm{Ga}$-DOTA-conjugated radiotracers ${ }^{68} \mathrm{Ga}-\mathrm{DOTA}-\mathrm{TOC},{ }^{68} \mathrm{Ga}-$ DOTA-TATE, ${ }^{68} \mathrm{Ga}$-DOTA-NOC, etc.) [19-21]. These improve both the detection sensitivity and patient convenience (only 2 hours is required to complete these tests), as well as a lower radiation dose and biliary excretion due to earlier imaging after radiotracer administration. Furthermore, these modalities are capable of quantifying the uptake of radiolabeled agents. Previous studies have shown that these gallium-based functional imaging methods are sensitive and deliver complementary information that is very useful for therapeutic decision-making $[20,22] .{ }^{68} \mathrm{Ga}-\mathrm{DOTA}-\mathrm{TOC}$ positron emission tomography (PET)/CT is available for use in Korea but is not currently reimbursed by the national health insurance system [23].

\section{Expert opinion}

Every patient diagnosed with a GEP-NET should be classified according to the revised WHO classification. As SSTRtargeting imaging may provide vital complementary information and thus influence therapeutic management, this procedure is recommended for newly diagnosed GEP-NET cases. 


\section{Somatostatin Analogs}

Octreotide LAR produced significantly improved progression-free survival (PFS) compared to a placebo in patients with an advanced midgut NET in the randomized phase III PROMID trial ( $\mathrm{n}=85,14.3$ months vs. 6.0 months; hazard ratio [HR], $0.34 ; 95 \%$ confidence interval $[\mathrm{CI}], 0.20$ to 0.59 ) [9]. In the phase III CLARINET trial, lanreotide autogel was associated with a superior PFS in advanced GEP-NET patients (median not reached vs. 18.0 months; HR, 0.47; 95\% CI, 0.30 to 0.73) [10]. Because of their excellent tolerability, even as long-term treatments, and proven clinical outcomes in both randomized trials and real-world clinical settings [24], these SSAs are recommended as initial treatment options. Although an assessment of SSTR positivity using SSTR-based imaging is generally recommended prior to SSA therapies, it may not be available in all hospitals. There have however been few prospective data for the effectiveness of SSAs in GEP-NET patients with a relatively high Ki-67 index $(>10 \%)$ and high tumor volumes. The PROMID study for octreotide LAR included a patient cohort with a Ki- $67 \leq 2 \%$ in 95\% of the cases and with hepatic tumor involvement $\leq 10 \%$ in $75 \%$ of the study population. The CLARINET study for lanreotide autogel enrolled patients with a Ki-67 $\leq 10 \%$ and hepatic tumor involvement $\leq 25 \%$ in $67 \%$ of the cases $[9,10]$. Other systemic therapeutic options such as targeted therapy or cytotoxic chemotherapy could be used for patients with a high Ki-67 index or high tumor volumes, but SSAs should not be precluded in these cases given their favorable toxicity profiles. ${ }^{68} \mathrm{Ga}$-based SSTR-targeting PET/CT may be helpful in predicting the efficacy outcomes of SSA treatments [23,25].

\section{Expert opinion}

Octreotide LAR is recommended for advanced midgut NETs and lanreotide autogel is recommended for advanced GEP-NETs and NETs of unknown primary origin, believed to be of GEP origin from imaging studies. Considering their favorable tolerability and proven clinical outcomes in randomized phase III trials, long-acting SSAs including octreotide LAR and lanreiotide autogel are generally recommended as a first-line therapy for unresectable or metastatic grade 1-2 GEP-NETs with a low or intermediate tumor volume. In Korea, octreotide LAR and lanreotide autogel are approved for use, and reimbursed through the national insurance system, for the management of advanced midgut NETs, and GEP-NETs or NETs of unknown primary origin, believed to be of GEP origin, respectively. Pretreatment assessments of SSTR-based imaging are recommended for the prediction of the efficacy of SSAs.

\section{Targeted Therapy}

Targeted therapies have been investigated for the management of unresectable or metastatic GEP-NETs. Despite extensive prior analysis, however, no single dominant driver mutation has emerged for GEP-NETs. Mammalian target of rapamycin (mTOR) inhibitors and anti-angiogenic agents have been mainly investigated as targeted therapies for these cancers and have shown promising clinical outcomes.

\section{Everolimus}

As somatic mutations in mTOR pathways such as TSC2, PTEN, PIK3CA, NF1, or IRS1 have been identified in pancreatic NETs, inhibiting mTOR pathways has been suggested as a potential therapeutic strategy for advanced GEP-NETs [26]. Based on the preliminary data for everolimus, including RADIANT-1 [27,28], large-randomized trials of this drug have been conducted for the management of advanced and progressive well-differentiated GEP-NETs.

The RADIANT- 3 trial was a randomized phase 3 trial comparing everolimus at a $10 \mathrm{mg} /$ day dose with a placebo for treating advanced pancreatic NETs. A total of 410 patients were included and the primary endpoint was the PFS determined by Response Evaluation Criteria in Solid Tumor. Everolimus significantly improved the median PFS to 11.0 months compared to 4.6 months obtained with the placebo ( $\mathrm{HR}, 0.35 ; 95 \% \mathrm{CI}, 0.27$ to 0.45 ) [11]. A role for everolimus in treating advanced non-functioning NETs of the lung or of gastrointestinal origin was investigated in the RADIANT-4 trial. In that subsequent randomized phase 3 trial, 302 patients were randomized 2:1 to either an everolimus or placebo arm. Patients receiving everolimus showed a significantly improved median PFS compared with those with placebo (11.0 months vs. 3.9 months; HR, $0.48 ; 95 \%$ CI, 0.35 to 0.67) [12]. Clinical efficacy of everolimus for grade 1-2 GEPNETs were also proven in Korean patients $[29,30]$. Although everolimus in combination with octreotide LAR produced an improved PFS (median, 16.4 months vs. 11.3 months; HR, 0.77; one-sided $p=0.026)$ compared to octreotide LAR in patients with grade 1-2 tumors with carcinoid syndrome (RADIANT-2 trial), that study failed to meet its primary endpoint from a statistical standpoint (PFS with one-sided $\mathrm{p}=0.025)$ [31].

The safety profiles of everolimus have been well investigated across multiple cancer types and no new adverse events specific for GEP-NETs have been described. Stomatitis is the most frequent complication of this drug and has been reported to arise at a rate of 40\%-64\% for all grades and at 3\%-19\% for grade $3-4[11,12,32,33]$. Hyperglycemia (overall, $10 \%-13 \%$; grade $3-4,3 \%-5 \%$ ) is also a common adverse event associated with everolimus treatments and requires meticulous moni- 
toring if patients are under management for subclinical or overt diabetes mellitus. Severe non-infectious pneumonitis is uncommon among GEP-NET cases (grade 3-4, 1\%-2\%) but may be life-threatening. Despite the increased toxicities from everolimus regimens compared to a placebo, no significant impairment to quality of life was documented in the RADIANT-4 trial [34].

\section{Sunitinib}

Although multiple anti-angiogenic agents, including sunitinib, sorafenib, bevacizumab, and pazopanib, have been investigated in prospective clinical trials for advanced GEPNETs [35-42], sunitinib is the only agent for which clinical outcomes have been evaluated in the randomized phase 3 trial for pancreatic NET $[13,36]$. This trial was originally designed to include 340 patients and randomize these patients into sunitinib or placebo arms at a 1:1 ratio [13]. That study was terminated at an early stage however because of the superior outcomes observed for sunitinib in the interim analysis. The sunitinib group showed a better PFS (median, 11.4 months) compared to the placebo group (5.5 months; HR, $0.42 ; 95 \%$ CI, 0.26 to 0.66$)$. The most frequent adverse events with sunitinib were diarrhea $(59 \%)$, nausea $(43 \%)$, vomiting $(34 \%)$, and fatigue (32\%).

\section{Expert opinion}

Everolimus is currently recommended for advanced grade 1-2 GEP-NETs, and sunitinib for advanced grade 1-2 pancreatic NET. Everolimus and sunitinib are both approved and reimbursed under the national insurance scheme in Korea for these indications and Korean prospective and retrospective studies support the findings from prior global phase 3 trials $[29,30]$. Considering the patient population included in the previous prospective trials and the accompanying toxicities, everolimus and sunitinib are generally recommended for progressive disease. However, for patients with SSTRnegative tumors, high tumor volumes, or Ki-67 >10\%, these agents could be used as an initial treatment.

\section{Peptide Receptor Radionuclide Therapy}

PRRT is a radiolabeled SSA therapy and has shown considerable promise for the treatment of advanced, well-differentiated NETs, the majority of which express high levels of SSTRs to which SSAs bind [43]. Initial efficacy was observed with ${ }^{90}$ Y-DOTA0-Tyr3-octreotide $\left({ }^{90} \mathrm{Y}\right.$-DOTATOC) and ${ }^{177} \mathrm{Lu}$ DOTA0-Tyr3-octreotate ( ${ }^{177} \mathrm{Lu}$-DOTATATE) [44-46]. ${ }^{177} \mathrm{Lu}-$ tetium is a beta- and gamma-emitting radionuclide with a maximum particle range of $2 \mathrm{~mm}$ and a half-life of 160 hours. Although ${ }^{177} \mathrm{Lu}$-based PRRT has shown promising efficacy in data published from Europe, there had been no evidence of this from previous randomized trials until the NETTER-1 trial [44-46].

NETTER-1 was a randomized controlled trial comparing ${ }^{177} \mathrm{Lu}$-DOTATATE plus octreotide LAR (30 mg every 4 weeks) with high-dose octreotide LAR (60 mg every 4 weeks) in patients with advanced, SSA-progressed, well-differentiated (grade 1-2), SSTR-positive, midgut NETs $(n=229)$ [14]. ${ }^{177} \mathrm{Lu}$-DOTATATE, at a dose of $7.4 \mathrm{GBq}$ every 8 weeks for four cycles, demonstrated an improved PFS (20-month PFS rates, $65.2 \%$ vs. $10.8 \%$; HR, 0.21 [95\% CI, 0.13 to 0.33$]$ ) and higher response rates ( $18 \%$ vs. $3 \%$ ) than high-dose octreotide LAR in SSTR-positive, well-differentiated midgut NET patients. In January 2018, the Food and Drug Administration (FDA) of the United States approved ${ }^{177} \mathrm{Lu}$-DOTATATE (Lutathera), for the treatment of SSTR-positive GEP-NETs on the basis of the NETTER-1 trial results. The adverse events arising from PRRT include myelosuppression (leukopenia, anemia or thrombocytopenia), impaired renal function, and carcinoid crisis. Although the Korean Ministry of Food and Drug Safety has not yet approved ${ }^{177} \mathrm{Lu}$-DOTATATE because of the absence of local clinical trials, it is currently available through the Korea Orphan \& Essential Drug Center. Treatments with ${ }^{177} \mathrm{Lu}$-DOTATATE are not reimbursed by the national insurance system in Korea. ${ }^{177} \mathrm{Lu}$-DOTATATE is currently under review for approval and reimbursement by regulatory agency in Korea.

As the NETTER-1 trial only included midgut NET patients, the efficacy of ${ }^{177} \mathrm{Lu}$-DOTATATE in patients with pancreatic NETs or non-midgut gastrointestinal NETs (i.e., of foregut and hindgut origin) has not been proven. Ongoing randomized trials including the COMPETE trial (grade 1-2 GEP-NETs) for ${ }^{177} \mathrm{Lu}$-EDOTREOTIDE and NETTER-2 trial (grade 2-3 GEP-NETs with a Ki-67 of 10\%-55\%) for ${ }^{177} \mathrm{Lu}$ DOTATATE will likely provide data for the outcomes of ${ }^{177}$ Lu-based PRRT in an overall GEP-NET patient cohort.

\section{Expert opinion}

${ }^{177} \mathrm{Lu}$-DOTATATE is recommended for progressive, well-differentiated GEP-NETs. While the U.S. FDA has approved Lutathera for overall GEP-NETs, the pivotal NETTER-1 trial only investigated midgut NET patients. Therefore, its use against pancreatic, foregut, or hindgut NETs should be cautiously done, and only on the basis of decisions from qualified multidisciplinary tumor boards, as there are no data from randomized trials on these treatments. Considering patient characteristics are different between Western and Korean NET patients and pivotal NETTER-1 trial included only few patients with Asian ethnicity, further investigation of the role of PRRT in Korean GEP-NETs patients are necessary. 
Table 4. Summary of expert opinion

\begin{tabular}{|c|c|}
\hline & Expert opinion \\
\hline \multirow[t]{2}{*}{ Diagnosis and staging } & GEP-NET should be classified according to the revised WHO classification. \\
\hline & SSTR-targeting imaging is recommended for newly diagnosed GEP-NET patients. \\
\hline \multicolumn{2}{|l|}{ Grade 1 and 2 NET } \\
\hline \multirow[t]{2}{*}{ Stomatostatin analog (SSA) } & $\begin{array}{l}\text { Octreotide LAR is recommended for advanced midgut NETs and lanreotide autogel is } \\
\text { recommended for advanced GEP-NETs and NETs of unknown primary origin, } \\
\text { believed to be of GEP origin from imaging studies. }\end{array}$ \\
\hline & $\begin{array}{l}\text { Long-acting SSAs are generally recommended as a first-line therapy for unresectable or } \\
\text { metastatic grade 1-2 GEP-NETs with a low or intermediate tumor volume. }\end{array}$ \\
\hline \multirow[t]{2}{*}{ Targeted therapy } & $\begin{array}{l}\text { Everolimus is recommended for advanced grade 1-2 GEP-NETs, and sunitinib for } \\
\text { advanced grade 1-2 pancreatic NET. }\end{array}$ \\
\hline & $\begin{array}{l}\text { Everolimus and sunitinib are generally recommended for progressive disease. } \\
\text { However, for patients with SSTR-negative tumors, high tumor volumes, or Ki-67 > 10\%, } \\
\text { these agents could be used as an initial treatment. }\end{array}$ \\
\hline \multirow[t]{2}{*}{ PRRT } & ${ }^{177} \mathrm{Lu}$-DOTATATE is recommended for progressive, well-differentiated GEP-NETs. \\
\hline & $\begin{array}{l}\text { The use of }{ }^{177} \text { Lu-DOTATATE against pancreatic, foregut or hindgut NETs should be } \\
\text { cautiously done, and only on the basis of decisions from qualified multidisciplinary } \\
\text { tumor boards, as there are no data from randomized trials. }\end{array}$ \\
\hline \multirow[t]{2}{*}{ Cytotoxic chemotherapy } & $\begin{array}{l}\text { For GEP-NET patients who progress while receiving an approved therapy, } \\
\text { cytotoxic chemotherapy is a feasible option. }\end{array}$ \\
\hline & $\begin{array}{l}\text { CAPTEM has shown promise with high response rates, particularly in pancreatic NET patients, } \\
\text { this regimen could be preferred for patients with high tumor volumes. }\end{array}$ \\
\hline \multicolumn{2}{|l|}{ Grade 3 NET or NEC } \\
\hline & $\begin{array}{l}\text { Etoposide plus cisplatin combination chemotherapy is the standard of care for patients } \\
\text { with a grade } 3 \text { NEC. }\end{array}$ \\
\hline & $\begin{array}{l}\text { There is no proven standard systemic therapy for grade } 3 \text { NET patients. } \\
\text { 5-FU-based chemotherapy or etoposide plus cisplatin could be used. }\end{array}$ \\
\hline
\end{tabular}

5-FU, 5-fluorouracil; CAPTEM, capecitabine plus temozolomide; GEP, gastroenteropancreatic; NEC, neuroendocrine carcinoma; NET, neuroendocrine tumor; PRRT, peptide receptor radionuclide therapy; SSA, somatostatin analog; SSTR, somatostatin receptor; WHO, World Health Organization.

\section{Cytotoxic Chemotherapy for Grade 1 or Grade 2 GEP-NETs}

Although there have been no large-randomized trials to date for cytotoxic chemotherapy in patients with advanced grade 1-2 GEP-NETs, 5-fluorouracil (5-FU) or doxorubicinbased chemotherapy have been widely used in daily practice, particularly for progressive tumors [47]. Streptozocin in combination with 5-FU has been reported to be somewhat effective against advanced GEP-NETs in several small studies [48-50], but this drug is not currently available in Korea.

Capecitabine plus temozolomide (CAPTEM) has gained popularity for the management of progressive GEP-NETs since this combination showed promising response rates of $70 \%$ in an initial small single-arm study [51,52]. A more recent randomized trial evaluated CAPTEM in comparison with temozolomide monotherapy for 144 pancreatic grade 1-2 NETs and reported that this combination regimen may be more effective than temozolomide monotherapy. However, the response rates for CAPTEM were only $33.3 \%$ in that study, which was somewhat inferior to the previous singlearm study $[15,51]$.

\section{Expert opinion}

For GEP-NET patients who progress while receiving an approved therapy such as SSAs or targeted therapeutics, cytotoxic chemotherapy is a feasible option. As CAPTEM has shown promise with high response rates, particularly in pancreatic NET patients, this regimen could be preferred for patients with high tumor volumes. CAPTEM is available for advanced pancreatic NET in Korea but is not reimbursed by the national insurance scheme. 


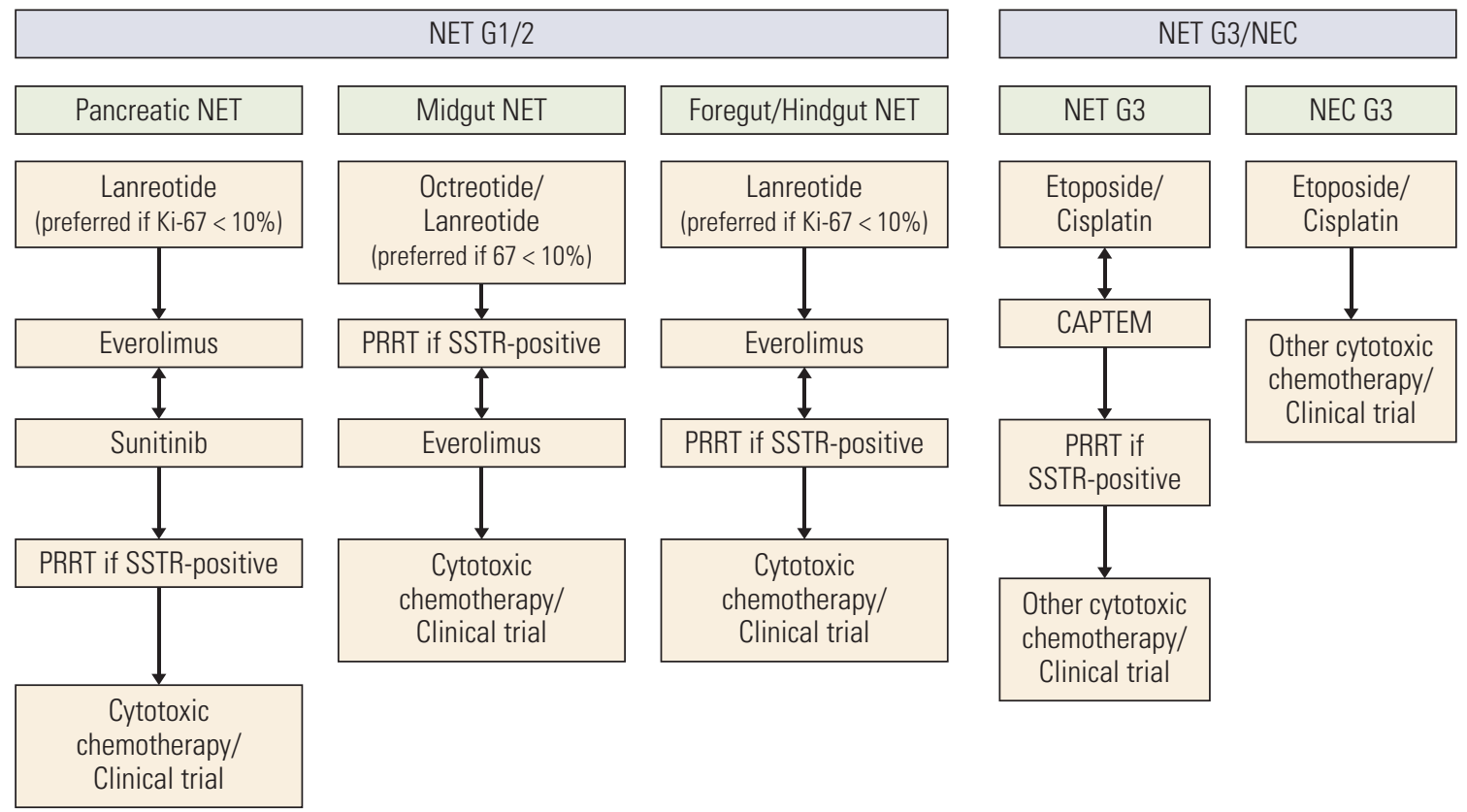

Fig. 1. The recommended approach of systemic therapy for advanced gastroenteropancreatic neuroendocrine tumors (NETs). CAPTEM, capecitabine plus temozolomide; NEC, neuroendocrine carcinoma; PRRT, peptide receptor radionuclide therapy; SSTR, somatostatin receptor.

\section{Systemic Therapy for Grade 3 NET and Neu- roendocrine Carcinomas of GEP Origin}

\section{Poorly differentiated grade 3 neuroendocrine carcinomas}

Grade 3 neuroendocrine carcinomas (NECs) should be considered a different disease entity than grade 1-2 NETs. Etoposide plus cisplatin is one of most widely used chemotherapy regimens in patients with a grade 3 NEC. A previous large retrospective study of 305 grade 3 NETs and NECs revealed that an etoposide plus cisplatin combination produced a response rate of $31 \%$, a median PFS of 4 months and a median overall survival of 12 months [53]. That study indicated that tumors with a Ki-67 > 55\% (likely a grade 3 NEC) were associated with better response rates ( $42 \%$ vs. 15\%) compared to those with a $\mathrm{Ki}-67<55 \%$ (likely a grade $3 \mathrm{NET}$ ), while survival outcomes were found to be better in patients with $\mathrm{Ki}-67<55 \%$ tumors. There is no proven second-line therapy after a patient has progressed while receiving etoposide plus cisplatin. Although ENETS guidelines recommend several cytotoxic chemotherapy regimens, including FOLFOX or FOLFIRI [8], these treatments have not been tested in randomized trials and not available in Korea. Irinitecan plus cisplatin was investigated for 18 NET / NEC patients in the single-arm phase 2 study based on the promising data on small cell lung cancer and showed modest activity against NEC patients $[54,55]$. Currently, irinotecan plus cisplatin is avail- able but not reimbursed for the management of advanced NEC patients in Korea. Although there is no currently approved targeted therapy or immunotherapy for the management of advanced grade 3 NEC patients, recent small phase 2 study showed promising efficacy outcomes with ipilimumab plus nivolumab for patients with non-pancreatic NEC [56].

\section{Well-differentiated grade 3 NETs}

Grade 3 NETs represent a new disease entity in the recently revised WHO classification [16,17]. As this entity was previously included within the grade 3 NEC classification, no data specific for this patient population are yet available. As a Nordic group reported less beneficial outcomes of etoposide plus cisplatin in patients with a Ki-67 <55\%, there is a consensus that this chemotherapy regimen may be suboptimal [53]. Although the therapeutic options used for grade 2 NETs such as everolimus, sunitinib, CAPTEM, or PRRT are listed as potential management strategies in the ESMO guideline for well-differentiated grade 3 GEP-NET patients [57], there is a lack of supporting data from prospective and real-world studies. Future studies are needed therefore to define the optimal treatment strategies for this patient subgroup. 


\section{Expert opinion}

An etoposide plus cisplatin combination chemotherapy is currently the standard of care for patients with a grade 3 NEC. While the prognosis is better with grade 3 NETs compared to grade 3 NECs, there is no proven standard systemic therapy for this patient group due to a lack of data. 5-FUbased chemotherapy or etoposide plus cisplatin could be used for grade 3 NETs.

\section{Conclusion}

GEP-NETs are a heterogeneous disease and yet to be fully understood in terms of clinical behaviors and biological features. The choice of systemic agents and their sequence of use should be personalized, based on the tumor primary sites and progression patterns. Recommended therapeutic approach for the management of Korean GEP-NETs patients and summary of expert opinion is presented in Table 4 and Fig. 1. Although this review focused on systemic therapies, local therapy including liver-directed therapies or palliative surgeries could be implemented as part of the management of advanced GEP-NETs. As multiple novel therapies are now available in daily practice, multidisciplinary approaches have become more important in the management of advanced GEP-NETs.

\section{Author Contributions}

Conceived and designed the analysis: Yoo C, Oh DY, Lee MA, Ryoo BY.

Collected the data: Yoo C, Oh CR, Kim ST, Bae WK, Choi HJ, Oh DY, Lee MA, Ryoo BY.

Contributed data or analysis tools: Yoo C, Oh CR, Kim ST, Bae WK, Choi HJ, Oh DY, Lee MA, Ryoo BY.

Performed the analysis: Yoo C, Oh CR, Oh DY, Lee MA, Ryoo BY. Wrote the paper: Yoo C, Oh CR, Kim ST, Bae WK, Choi HJ, Oh DY, Lee MA, Ryoo BY.

\section{Conflicts of Interest}

$C Y$ has received research grants and honoraria from Ipsen and honoraria from Novartis. S-TK, WKB, H-JC, M-AL, and B-YR have received honoraria from Ipsen.

\section{References}

1. Dasari A, Shen C, Halperin D, Zhao B, Zhou S, Xu Y, et al. Trends in the incidence, prevalence, and survival outcomes in patients with neuroendocrine tumors in the United States. JAMA Oncol. 2017;3:1335-42.

2. Yao JC, Hassan M, Phan A, Dagohoy C, Leary C, Mares JE, et al. One hundred years after "carcinoid": epidemiology of and prognostic factors for neuroendocrine tumors in 35,825 cases in the United States. J Clin Oncol. 2008;26:3063-72.

3. Frilling A, Modlin IM, Kidd M, Russell C, Breitenstein S, Salem $\mathrm{R}$, et al. Recommendations for management of patients with neuroendocrine liver metastases. Lancet Oncol. 2014;15:e8-21.

4. Goksu SY, Ozer M, Beg MS, Sanford NN, Ahn C, Fangman $\mathrm{BD}$, et al. Racial/ethnic disparities and survival characteristics in non-pancreatic gastrointestinal tract neuroendocrine tumors. Cancers (Basel). 2020;12:2990.

5. Gastrointestinal Pathology Study Group of Korean Society of Pathologists; Cho MY, Kim JM, Sohn JH, Kim MJ, Kim $\mathrm{KM}$, et al. Current trends of the incidence and pathological diagnosis of gastroenteropancreatic neuroendocrine tumors (GEP-NETs) in Korea 2000-2009: multicenter study. Cancer Res Treat. 2012;44: 157-65.

6. Kim SJ, Kim JW, Oh DY, Han SW, Lee SH, Kim DW, et al. Clinical course of neuroendocrine tumors with different origins (the pancreas, gastrointestinal tract, and lung). Am J Clin Oncol. 2012;35:549-56.

7. Kim SJ, Kim JW, Han SW, Oh DY, Lee SH, Kim DW, et al. Biological characteristics and treatment outcomes of metastatic or recurrent neuroendocrine tumors: tumor grade and meta- static site are important for treatment strategy. BMC Cancer. 2010;10:448.

8. Pavel M, O'Toole D, Costa F, Capdevila J, Gross D, Kianmanesh $\mathrm{R}$, et al. ENETS consensus guidelines update for the management of distant metastatic disease of intestinal, pancreatic, bronchial neuroendocrine neoplasms (NEN) and NEN of unknown primary site. Neuroendocrinology. 2016;103:172-85.

9. Rinke A, Muller HH, Schade-Brittinger C, Klose KJ, Barth $\mathrm{P}$, Wied M, et al. Placebo-controlled, double-blind, prospective, randomized study on the effect of octreotide LAR in the control of tumor growth in patients with metastatic neuroendocrine midgut tumors: a report from the PROMID Study Group. J Clin Oncol. 2009;27:4656-63.

10. Caplin ME, Pavel M, Cwikla JB, Phan AT, Raderer M, Sedlackova $\mathrm{E}$, et al. Lanreotide in metastatic enteropancreatic neuroendocrine tumors. N Engl J Med. 2014;371:224-33.

11. Yao JC, Shah MH, Ito T, Bohas CL, Wolin EM, Van Cutsem $\mathrm{E}$, et al. Everolimus for advanced pancreatic neuroendocrine tumors. N Engl J Med. 2011;364:514-23.

12. Yao JC, Fazio N, Singh S, Buzzoni R, Carnaghi C, Wolin E, et al. Everolimus for the treatment of advanced, non-functional neuroendocrine tumours of the lung or gastrointestinal tract (RADIANT-4): a randomised, placebo-controlled, phase 3 study. Lancet. 2016;387:968-77.

13. Raymond E, Dahan L, Raoul JL, Bang YJ, Borbath I, LombardBohas C, et al. Sunitinib malate for the treatment of pancreatic neuroendocrine tumors. N Engl J Med. 2011;364:501-13.

14. Strosberg J, El-Haddad G, Wolin E, Hendifar A, Yao J, Chasen 
B, et al. Phase 3 trial of (177)Lu-dotatate for midgut neuroendocrine tumors. N Engl J Med. 2017;376:125-35.

15. Kunz PL, Catalano PJ, Nimeiri H, Fisher GA, Longacre TA, Suarez CJ, et al. A randomized study of temozolomide or temozolomide and capecitabine in patients with advanced pancreatic neuroendocrine tumors: a trial of the ECOG-ACRIN Cancer Research Group (E2211). J Cancer Oncol. 2018; 36:4004

16. Kloeppel G. Neuroendocrine neoplasms of the pancreas. In: Lloyd RV, Osamura RY, Kloppel G, Rosai J, editors. WHO classification of tumours of endocrine organs. 4 th ed. Lyon: IARC Press; 2017. p. 209-40.

17. WHO Classification of Tumours Editorial Board. WHO classification of tumours: digestive system tumours. 5th ed. Lyon: IARC Press; 2019.

18. Oberg K, Modlin IM, De Herder W, Pavel M, Klimstra D, Frilling $\mathrm{A}$, et al. Consensus on biomarkers for neuroendocrine tumour disease. Lancet Oncol. 2015;16:e435-46.

19. Deppen SA, Blume J, Bobbey AJ, Shah C, Graham MM, Lee $P$, et al. 68Ga-DOTATATE compared with 111In-DTPA-octreotide and conventional imaging for pulmonary and gastroenteropancreatic neuroendocrine tumors: a systematic review and meta-analysis. J Nucl Med. 2016;57:872-8.

20. Ruf J, Heuck F, Schiefer J, Denecke T, Elgeti F, Pascher A, et al. Impact of multiphase 68Ga-DOTATOC-PET/CT on therapy management in patients with neuroendocrine tumors. Neuroendocrinology. 2010;91:101-9.

21. Deppen SA, Liu E, Blume JD, Clanton J, Shi C, Jones-Jackson LB, et al. Safety and Efficacy of 68Ga-DOTATATE PET/CT for diagnosis, staging, and treatment management of neuroendocrine tumors. J Nucl Med. 2016;57:708-14.

22. Frilling A, Sotiropoulos GC, Radtke A, Malago M, Bockisch A, Kuehl H, et al. The impact of $68 \mathrm{Ga}$-DOTATOC positron emission tomography/computed tomography on the multimodal management of patients with neuroendocrine tumors. Ann Surg. 2010;252:850-6.

23. Kim YI, YooC, OhSJ, LeeSJ, KangJ, Hwang HS, etal. Tumour-toliver ratio determined by [(68)Ga]Ga-DOTA-TOC PET/CT as a prognostic factor of lanreotide efficacy for patients with welldifferentiated gastroenteropancreatic-neuroendocrine tumours. EJNMMI Res. 2020;10:63.

24. Kang J, Yoo C, Hwang HS, Hong SM, Kim KP, Kim SY, et al. Efficacy and safety of lanreotide in Korean patients with metastatic, well-differentiated gastroenteropancreatic-neuroendocrine tumors: a retrospective analysis. Invest New Drugs. 2019;37:763-70.

25. Lee H, Eads JR, Pryma DA. 68Ga-DOTATATE positron emission tomography-computed tomography quantification predicts response to somatostatin analog therapy in gastroenteropancreatic neuroendocrine tumors. Oncologist. 2021;26:21-9.

26. Chan J, Kulke M. Targeting the mTOR signaling pathway in neuroendocrine tumors. Curr Treat Options Oncol. 2014;15:365-79.

27. Yao JC, Phan AT, Chang DZ, Wolff RA, Hess K, Gupta S, et al. Efficacy of RAD001 (everolimus) and octreotide LAR in advanced low- to intermediate-grade neuroendocrine tumors: results of a phase II study. J Clin Oncol. 2008;26:4311-8.

28. Yao JC, Lombard-Bohas C, Baudin E, Kvols LK, Rougier P, Ruszniewski $P$, et al. Daily oral everolimus activity in patients with metastatic pancreatic neuroendocrine tumors after failure of cytotoxic chemotherapy: a phase II trial. J Clin Oncol. 2010;28:69-76.

29. Oh DY, Kim TW, Park YS, Shin SJ, Shin SH, Song EK, et al. Phase 2 study of everolimus monotherapy in patients with nonfunctioning neuroendocrine tumors or pheochromocytomas/paragangliomas. Cancer. 2012;118:6162-70.

30. Yoo C, Cho H, Song MJ, Hong SM, Kim KP, Chang HM, et al. Efficacy and safety of everolimus and sunitinib in patients with gastroenteropancreatic neuroendocrine tumor. Cancer Chemother Pharmacol. 2017;79:139-46.

31. Pavel ME, Hainsworth JD, Baudin E, Peeters M, Horsch D, Winkler RE, et al. Everolimus plus octreotide long-acting repeatable for the treatment of advanced neuroendocrine tumours associated with carcinoid syndrome (RADIANT-2): a randomised, placebo-controlled, phase 3 study. Lancet. 2011; 378:2005-12.

32. Motzer RJ, Escudier B, Oudard S, Hutson TE, Porta C, Bracarda $S$, et al. Efficacy of everolimus in advanced renal cell carcinoma: a double-blind, randomised, placebo-controlled phase III trial. Lancet. 2008;372:449-56.

33. Baselga J, Campone M, Piccart M, Burris HA 3rd, Rugo HS, Sahmoud T, et al. Everolimus in postmenopausal hormonereceptor-positive advanced breast cancer. N Engl J Med. 2012; 366:520-9.

34. Pavel ME, Singh S, Strosberg JR, Bubuteishvili-Pacaud L, Degtyarev E, Neary MP, et al. Health-related quality of life for everolimus versus placebo in patients with advanced, nonfunctional, well-differentiated gastrointestinal or lung neuroendocrine tumours (RADIANT-4): a multicentre, randomised, double-blind, placebo-controlled, phase 3 trial. Lancet Oncol. 2017;18:1411-22.

35. Strosberg JR, Weber JM, Choi J, Campos TL, Valone TL, Han $\mathrm{G}$, et al. A phase II clinical trial of sunitinib following hepatic transarterial embolization for metastatic neuroendocrine tumors. Ann Oncol. 2012;23:2335-41.

36. Kulke MH, Lenz HJ, Meropol NJ, Posey J, Ryan DP, Picus J, et al. Activity of sunitinib in patients with advanced neuroendocrine tumors. J Clin Oncol. 2008;26:3403-10.

37. Phan AT, Halperin DM, Chan JA, Fogelman DR, Hess KR, Malinowski $\mathrm{P}$, et al. Pazopanib and depot octreotide in advanced, well-differentiated neuroendocrine tumours: a multicentre, single-group, phase 2 study. Lancet Oncol. 2015;16:695-703.

38 Grande E, Capdevila J, Castellano D, Teule A, Duran I, Fuster J, et al. Pazopanib in pretreated advanced neuroendocrine tumors: a phase II, open-label trial of the Spanish Task Force Group for Neuroendocrine Tumors (GETNE). Ann Oncol. 2015;26:1987-93.

39. Ahn HK, Choi JY, Kim KM, Kim H, Choi SH, Park SH, et al. Phase II study of pazopanib monotherapy in metastatic gastroenteropancreatic neuroendocrine tumours. Br J Cancer. 2013;109:1414-9.

40. Chan JA, Stuart K, Earle CC, Clark JW, Bhargava P, Miksad R, 
et al. Prospective study of bevacizumab plus temozolomide in patients with advanced neuroendocrine tumors. J Clin Oncol. 2012;30:2963-8.

41. Castellano D, Capdevila J, Sastre J, Alonso V, Llanos M, Garcia-Carbonero $\mathrm{R}$, et al. Sorafenib and bevacizumab combination targeted therapy in advanced neuroendocrine tumour: a phase II study of Spanish Neuroendocrine Tumour Group (GETNE0801). Eur J Cancer. 2013;49:3780-7.

42. Yao JC, Phan A, Hoff PM, Chen HX, Charnsangavej C, Yeung $\mathrm{SC}$, et al. Targeting vascular endothelial growth factor in advanced carcinoid tumor: a random assignment phase II study of depot octreotide with bevacizumab and pegylated interferon alpha-2b. J Clin Oncol. 2008;26:1316-23.

43. Brabander T, Teunissen JJ, Van Eijck CH, Franssen GJ, Feelders RA, de Herder WW, et al. Peptide receptor radionuclide therapy of neuroendocrine tumours. Best Pract Res Clin Endocrinol Metab. 2016;30:103-14.

44. Kwekkeboom DJ, de Herder WW, Kam BL, van Eijck $\mathrm{CH}$, van Essen M, Kooij PP, et al. Treatment with the radiolabeled somatostatin analog [177 Lu-DOTA 0,Tyr3]octreotate: toxicity, efficacy, and survival. J Clin Oncol. 2008;26:2124-30.

45. Kwekkeboom DJ, Teunissen JJ, Bakker WH, Kooij PP, de Herder WW, Feelders RA, et al. Radiolabeled somatostatin analog [177Lu-DOTA0,Tyr3]octreotate in patients with endocrine gastroenteropancreatic tumors. J Clin Oncol. 2005;23:2754-62.

46. Sabet A, Biersack HJ, Ezziddin S. Advances in peptide receptor radionuclide therapy. Semin Nucl Med. 2016;46:40-6.

47. Kouvaraki MA, Ajani JA, Hoff P, Wolff R, Evans DB, Lozano R, et al. Fluorouracil, doxorubicin, and streptozocin in the treatment of patients with locally advanced and metastatic pancreatic endocrine carcinomas. J Clin Oncol. 2004;22:4762-71.

48. Moertel CG, Lefkopoulo M, Lipsitz S, Hahn RG, Klaassen D. Streptozocin-doxorubicin, streptozocin-fluorouracil or chlorozotocin in the treatment of advanced islet-cell carcinoma. $\mathrm{N}$ Engl J Med. 1992;326:519-23.

49. Dilz LM, Denecke T, Steffen IG, Prasad V, von Weikersthal LF, Pape UF, et al. Streptozocin/5-fluorouracil chemotherapy is associated with durable response in patients with advan- ced pancreatic neuroendocrine tumours. Eur J Cancer. 2015; 51:1253-62.

50. Clewemar Antonodimitrakis P, Sundin A, Wassberg C, Granberg D, Skogseid B, Eriksson B. Streptozocin and 5-fluorouracil for the treatment of pancreatic neuroendocrine tumors: efficacy, prognostic factors and toxicity. Neuroendocrinology. 2016;103:345-53.

51. Strosberg JR, Fine RL, Choi J, Nasir A, Coppola D, Chen DT, et al. First-line chemotherapy with capecitabine and temozolomide in patients with metastatic pancreatic endocrine carcinomas. Cancer. 2011;117:268-75.

52. Fine RL, Gulati AP, Krantz BA, Moss RA, Schreibman S, Tsushima DA, et al. Capecitabine and temozolomide (CAPTEM) for metastatic, well-differentiated neuroendocrine cancers: the Pancreas Center at Columbia University experience. Cancer Chemother Pharmacol. 2013;71:663-70.

53. Sorbye H, Welin S, Langer SW, Vestermark LW, Holt N, Osterlund $\mathrm{P}$, et al. Predictive and prognostic factors for treatment and survival in 305 patients with advanced gastrointestinal neuroendocrine carcinoma (WHO G3): the NORDIC NEC study. Ann Oncol. 2013;24:152-60.

54. Kulke MH, Wu B, Ryan DP, Enzinger PC, Zhu AX, Clark $\mathrm{JW}$, et al. A phase II trial of irinotecan and cisplatin in patients with metastatic neuroendocrine tumors. Dig Dis Sci. 2006;51:1033-8

55. Noda K, Nishiwaki Y, Kawahara M, Negoro S, Sugiura T, Yokoyama A, et al. Irinotecan plus cisplatin compared with etoposide plus cisplatin for extensive small-cell lung cancer. N Engl J Med. 2002;346:85-91.

56. Patel SP, Othus M, Chae YK, Giles FJ, Hansel DE, Singh PP, et al. A phase II basket trial of dual anti-CTLA-4 and antiPD-1 blockade in rare tumors (DART SWOG 1609) in patients with nonpancreatic neuroendocrine tumors. Clin Cancer Res. 2020;26:2290-6.

57. Pavel M, Oberg K, Falconi M, Krenning EP, Sundin A, Perren A, et al. Gastroenteropancreatic neuroendocrine neoplasms: ESMO clinical practice guidelines for diagnosis, treatment and follow-up. Ann Oncol. 2020;31:844-60. 